Ĭgdır Üniversitesi Fen Bilimleri Enstitüsü Dergisi, 11(Özel Sayı): 3476-3481, 2021

Journal of the Institute of Science and Technology, 11(Special Issue): 3476-3481, 2021

Bitki Koruma / Plant Protection

ISSN: 2146-0574, eISSN: 2536-4618

DOI: 10.21597/jist.1028429

Araştırma Makalesi / Research Article

Geliş tarihi / Received: 27.11.2021

Kabul tarihi / Accepted: 15.12.2021

Atıf İçin: Ertaş Öz MN, Turgay EB, Bozdemir Ç, Bülbül S, 2021. Bazı Çörek Otu Tohumlarında Fungal Floranın Tespiti. Iğdır Üniversitesi Fen Bilimleri Enstitüsü Dergisi, 11(Özel Sayı): 3476-3481.

To Cite: Ertas Oz MN, Turgay EB, Bozdemir C, Bulbul S, 2021. Determination of Fungal Flora in Some Black Cumin Seeds. Journal of the Institute of Science and Technology, 11(Special Issue): 3476-3481.

\title{
Bazı Çörek Otu Tohumlarında Fungal Floranın Tespiti
}

\section{Merve Nur ERTAŞ ÖZ*, Emine Burcu TURGAY, Çiğdem BOZDEMIR, Sibel BÜLBÜL}

ÖZET: Çörek otu (Nigella sativa L.), Ranunculaceae familyasına bağlı tek yıllık tıbbi ve aromatik bir bitkidir. İçerdiği çeşitli faydalı yağlardan ötürü sağlık sektöründe kullanılan çörek otunun Türkiye'de ki ekim alanları ise gitgide artı̧̧ göstermektedir. 2012 yılında çörek otu 2.299 da arazide 161 ton üretime sahip iken, 2019 y1lı verilerine göre 37.085 da alana yükselmiş olup toplam üretim ise 3.603 tona çıkmıştır. Ülkemizde ise tescil almış tek bir çörek otu çeşidi (Çameli) bulunmakta olup, çörek otu ile ilgili çeşitli ıslah çalışmaları yürütülmektedir. Bu çalışma da ise Tarla Bitkileri Merkez Araştırma Enstitüsüne bağlı İkizce Araştırma Çiftliği, Haymana' da çörek otu sslah materyallerinden elde edilen çörek otu tohumlarındaki fungal çeşitliliğin tespiti yapılmıştır. 2200 tohum ISTA kurallarına göre (blotter ve deep freeze blotter metodu ile) muamele edilerek 6 farklı fungus cinsi elde edilmiştir ve toplamda 772 tohumda bu funguslar tespit edilmiştir. Bu hastalıklı tohumların 432'si Alternaria sp. (\%55.96), 184'ü Ulocladium sp. (\%23.84), 82'si Penicillium sp. (\%10.62), 37'si Cladosporium sp. (\%4.8), 12'si Fusarium spp. (\%1.55), 8'i Rhizopus sp. (\%1.04) ve 17'si ise steril fungus (\%2.20) olarak tespit edilmiştir.

Anahtar Kelimeler: Çörekotu, Nigella sativa L., Tohum mikrobiyomu, Fungal çeşitlilik, Fungal populasyon, Mikoflora

\section{Determination of Fungal Flora in Some Black Cumin Seeds}

ABSTRACT: Black cumin (Nigella sativa L.) is an annual medicinal and aromatic plant belonging to the Ranunculaceae family. The cultivation areas of black cumin, which is used in the health sector due to the various beneficial oils it contains, are gradually increasing in Turkey. While black cumin had a production of 161 tons on 2,299 da land in 2012, it increased to 37,085 da area according to 2019 data, and the total production increased to 3,603 tons. In our country, there is only one registered black cumin variety (Çameli), and various breeding studies are carried out on black cumin . In this study, the fungal diversity in black cumin seeds obtained from black cumin breeding materials in İkizce Research Farm, Haymana, affiliated to the Field Crops Central Research Institute was determined. 6 different fungi were obtained by treating 2200 seeds according to ISTA rules (blotter and deep freeze blotter method) and 772 diseased seeds were obtained. Of the diseased seeds, 432were Alternaria sp. (55.96\%), 184 of them were Ulocladium sp. (23.84\%), 82 of them Penicillium sp. (10.62\%), 37 of them were Cladosporium sp. (4.8\%), 12 of which were Fusarium sp. (1.55\%), 8 of them were Rhizopus sp. (1.04\%) and 17 $(2.20 \%)$ were detected as sterile fungi.

Keywords: Black cumin, Nigella sativa L., Seed microbiome, Fungal diversity, Fungal population, Mycflora

\footnotetext{
${ }^{1}$ Merve Nur ERTAŞ ÖZ (Orcid ID: 0000-0001-9689-179X), Emine Burcu TURGAY (Orcid ID: 0000-0003-1150-4901), Çiğdem BOZDEMİR (Orcid ID: 0000-0002-8719-6565), Sibel BÜLBÜL(Orcid ID: 0000-0001-5263-461X) Tarla Bitkileri Merkez Araştırma Enstititüsü

*Sorumlu Yazar/Corresponding Author: Merve Nur ERTAŞ ÖZ, m.nur.ertas@gmail.com

Makale 15-18 Ekim 2021 tarihlerinde Iğdır'da düzenlenen “Uluslararası Katılımlı 7. Tohumculuk Kongresi’nde” sözlü bildiri olarak sunulmuştur.
} 


\section{Bazı Çörek Otu Tohumlarında Fungal Floranın Tespiti}

\section{GİRIŞ}

Çörek otu (Nigella sativa) tek yıllık çiçekli bir bitki olmakla birlikte 20-30 cm boyuna kadar uzamaktadır ve mızrak şeklinde yaprakları bulunmaktadır. Çiçekleri ise narin ve 5-10 cm arası değişen taç yapraklarına sahiptir. Çiçeklerin rengi sarı, beyaz, pembe, açık mavi veya açık mor olabilir. Meyveleri büyük olup, kapsülleri 3-7 bölmeden oluşur ve tohumlar bu kapsüllerin içerisinde gelişir. Tohumlar siyah renkli olup düz, oblong veya farklı şekillerde olabilmektedir. Tohum boyu genellikle $0.2 \mathrm{~cm}$ uzunluğunda, eni ise $0.1 \mathrm{~cm}$ çapında olabilir (Goreja, 2003). Mısır ve Doğu Akdeniz bölgesine özgü olan bu bitki genellikle Akdeniz, Orta Doğu, Orta Avrupa ve Batı Asya'da kurak ve yarı kurak iklimlerde yetiştirilmektedir (Randhawa ve Alghamdi, 2011). Çörek otu gıdalarda kullanılması ile birlikte, geleneksel tıp ve endüstriyel farmokoloji alanlarında oldukça popülerdir. İçerdiği yağlar ve timokinon aktif maddesinden ötürü diyabet, hipertansiyon, astım ve bronşit gibi hastalıkların tedavisinde kullanılmaktadır (Forouzanfar ve ark., 2014). Diğer yandan ülkemizde çörek otu yetiştiriciliği gittikçe artmaktadır. 2012 yılında 5 ilde üretimi olan çörek otunun TUİK 2019 yılında 24 ilde çörek otu yetiştiriciliğinin yapıldığını rapor etmiştir. Aynı veriler 2019 yılı için Türkiye'de toplamda 37.085 da alanda 3.603 ton üretim olduğunu göstermektedir (Anonim, 2021) (Çizelge 1).

Çizelge 1. Türkiye'de çörek otu bitkisi ekim alanı (da) ve üretim miktarı (ton) (Anonim 2021)

\begin{tabular}{cccc} 
Yıllar & Ekilis Alanı (da) & Üretim Miktarı (ton) & Verim $\left(\mathbf{k g ~ d a}^{\mathbf{- 1}}\right)$ \\
$\mathbf{2 0 1 2}$ & 2.299 & 161 & 70 \\
$\mathbf{2 0 1 3}$ & 3.261 & 352 & 108 \\
$\mathbf{2 0 1 4}$ & 1.717 & 140 & 82 \\
$\mathbf{2 0 1 5}$ & 4.681 & 425 & 91 \\
$\mathbf{2 0 1 6}$ & 23.160 & 2.527 & 109 \\
$\mathbf{2 0 1 7}$ & 32.560 & 3.094 & 95 \\
$\mathbf{2 0 1 8}$ & 33.864 & 3.322 & 98 \\
$\mathbf{2 0 1 9}$ & 37.085 & 3.603 & 97 \\
\hline
\end{tabular}

Yeni bitkilerin oluşumunda önemli rol oynayan tohumlar, ayrıca karmaşık mikrobiyal topluluklarında taşıyıcısıdır. Bitki gelişiminde ve sağlığında yararlı veya zararlı olabilen bu organizmaların (Barret ve ark., 2015) tohumlarda oluşturduğu çeşitlilik tohum mikrobiyomunu oluşturmaktadır ve tohum mikrobiyomu son zamanlarda yapılan moleküler çalışmalar ile tohum sağlığı alanında gün geçtikçe önemli bir konu haline gelmektedir.

Abiyotik ve biyotik faktörler nedeniyle tohumlar zarar görebilirler. Yüksek sıcaklık, tohum hazırlığı sırasında uygun olamayan dezenfektanların kullanımı tohumlarda abiyotik zarar neden olabilir.

Biyotik faktörleden en önemlisi ise fungusların neden olduğu zararlardır. Tohum florasında en yayın görülen patojenik olan fungal etmenler; Trichothecium, Penicillium, Aspergillus, Alteranria, Botrytis, Fusarium, Rhizophus, ve Mucor türleridir (Gürer, 2000). Bu etmenler tohumun çimlenme yeteneğini ve sağlı̆̆ını olumsuz etkiler.

Çimlenme sırasında tohumlar toprak kökenli patojenlere karşı hassas olabilirler (Bever ve ark., 2015) ve bu hassasiyet bitki gelişimini olumsuz etkileyebilir. Tohum çimlenmesi sırasında gerçekleşen fizyolojik süreçte, tohum etrafındaki toprakta besin maddeleri açığa çıkar. Bu besinlerin oluşturduğu karbon bileşiklerinin mevcudiyeti ile çimlenen tohum etrafında spermosfer olarak adlandırılan bir kuşak oluşturur Bu kuşak tohum kökenli patojenlerile toprak patojenlerinin yoğun rekabete girdiği yerdir ve hastalık gelişimi için de önemli bir alandır (Nelson, 2004). Bu esnada tohumdaki mikrobiyal canlılar toprak kökenli patojenik mikroorganizmaların aktivitelerini engelleyebilir (Hardoim ve ark. 2015; Nelson, 2018; Mukherjee ve ark. 2020).

Tohum ile etkileşime girmiş mikroorganizmalar bitkinin çimlenme aşamasından hasat aşamasına kadar bitki üzerinde taşınmaktadırlar. Bu taşınım vertikal (tohum dokusu içerisine yerleşmiş olan 
endofitik mikrobiyotanın taşınma şeklidir) veya horizontal (tohum yüzeyine yerleşmiş epifitik mikrobiyotanın taşınım şeklidir) yollar ile gerçekleşmektedir (Nelson, 2018). Bu taşınımlar sayesinde mikroorganizmlar, bitkinin farklı gelişim evrelerinde bitki ile interaksiyona girerek onu dışarıdan gelebilecek biyotik veya abiyotik etmenlere karşı koruyabilir (Hardoim ve ark., 2015; Mukherjee ve ark., 2020; Nelson, 2018). Özellikle vertikal olarak taşınan endofitler, bitkilerde biyotik veya abiyotik faktörlere karşı bitkiye uyarılmış dayanıklılık (Induced Systemic Resistance) kazandırarak patojenlere karşı daha yüksek toleransa sahip olmalarını sağlayabilir (Hardoim ve ark., 2015).

Bu çalışmada tohum ve dolayısı ile bitki sağlığında önemli rol oynayan çörek otu tohumlarındaki floranın tespiti amaçlanmıştır.

\section{MATERYAL VE METOT}

Çörek otu tohumları, Tarla Bitkileri Merkez Araştırma Enstitüsüne bağlı İkizce Araştırma çiftliğinde geliştirilen çörek otu ıslah materyallerinden, farklı parsellerden toplanmıştır. Laboratuvara getirilen tohumlar ISTA (International Seed Testing Association) kuralları çerçevesinde blotter ve deepfreeze blotter yöntemi ile muamele edilerek tohumda bulunan fungusların izolasyonu gerçekleştirilmiştir.

Blotter Metodu: Tohumlar ayıklandıktan sonra \%1'lik NaOCl çözeltisinde $3 \mathrm{dk}$. ve ardından 3 kere distile sudan geçirilmiştir. Yüzey sterilizasyonuna tabii tutulan tohumlar 3 kat nemlendirilmiş steril kurutma kağıtlarına her bir petride 20 adet olacak şekilde her bir örnek için 200 tohum ekilerek $20 \pm 2$ ${ }^{\circ} \mathrm{C}$ ' de 7 gün boyunca inkübasyona bırakılmıştır.

Deep-freeze Blotter Metodu: Tohumları blotter metodunda tanımlandı̆̆ sonra, petriler 24 saat a $20 \pm 2{ }^{\circ} \mathrm{C}^{\prime}$ de ardından 24 saat $-20^{\circ} \mathrm{C}^{\prime}$ de tutulmuştur. Bu işlemden sonra $20 \pm 2$ ${ }^{\circ} \mathrm{C}$ 'de 5 gün boyunca inkübe edilmiştir.

İnkübasyon sonrasında tohumlarda gelişen funguslar stereo ve 1şı mikroskobu kullanılarak incelenmiştir. Patates Dektroz Agar (PDA) içeren eğik tüplerde $+4^{0} \mathrm{C}$ 'de muhafaza altına alınmıştır. Funguslar koloni, konidi ve konidiofor yapılarına göre morfolojik karakterizasyonu yapılarak tanıları Patates Dektroz Agar (PDA) ve Synthetic low-nutrient Agar (SNA) ortamlarında geliştirilerek gerçekleştirilmiştir (Booth, 1977; Nelson ve ark., 1983).

\section{BULGULAR VE TARTIŞMA}

Çörek otu fungal florasının belirlenmesi amaciyla blotter ve deep freze blotter metodu uygulanmıştır. Her birinden iki yüz tohum olacak şekilde toplamda 1200 tohuma blotter metodu, toplamda 1000 tohuma ise deep freeze blotter metodu uygulanmıştır.

Toplamda incelenen 2200 tohumun toplamda 772 tanesi hastalıklı bulunmuştur ve bunlardan 432 adedi Alternaria sp. (\% 55.96), 184'ü Ulocladium sp. (\%23.84), 82'si Penicillium sp. (\% 10.62), 37'si Cladosporium sp. (\%4.8), 12'si Fusarium sp. (\%1.55), 8'i Rhizopus sp. (\%1.04) ve 17'si steril fungus (\%2.20) olarak tanımlanmıştır.

Nelson (2017), endofitik fungusların çoğunlukla Ascomycota bölümü Dothideomycetes sınıfına ait olduğunu rapor etmiştir. Çalışmada elde edilen fungus cinslerinden üçü ise Dothideomycetes sınıfina ait olup, bir tanesi (Rhizopus spp.) Ascomycota bölümüne ait değildir.

Çörek otu tohum fungal florası ile ilgili dünyada yapılan çalışmalar sınırlıdır. Mısırda yapılan bir çalışmada 88 çörek otu tohum örneği marketlerden toplanmış ve hem blotter hemde deep-freezing metodları kullanılarak tohumlardaki fungal flora belirlenmiştir. Toplamda 20 farklı cinse ait 37 tür teşhis edilmiştir (Elwakil ve Ghoneem, 1999). Bir başka çalışmada ise Irak'da farklı lokasyonlardan toplanan çörek otu tohumları incelenmiş ve 9 fungus cinsi (Aspergillus , Penicillium, Alternaria, Cladosporium 
, Fusarium, Ulocladium, Rhizoctonia, Stemphyllium ve Chaetomium ) tespit edilmiştir (Al-Zubaide ve ark., 2014).

Hindistan'da yürüttülen bir çalışmada hasat öncesi, hasat sonrası ve depoda bulunan çörek otu tohumlarının fungal florası incelemiş, 17 cinse ait 32 fungus türü elde etmişlerdir (Anwar ve Ansari, 2016). Hindistan'da yapılan bir başka çalışmada ise 40 farklı çörek otu tohumu örnekleri incelenmiş ve 17 farklı fungus türü rapor edilmiştir (Fatima ve Khot, 2015).

Elde ettiğimiz sonuçlar, yapılmış çalışmalarla karşılaştırıldığında, fungal flora çeşitliliğinin daha az olduğu görülmektedir. Bu farklılığın sebebinin tohum mikrobiyomunun şekil almasında rol oynayan faktörler ile ilgili olabileceği gibi konukçu bitki, bitkinin genotipi veya çevre koşullarından kaynaklanmış olabileceği düşünülmektedir (Latz ve ark., 2021; Morales-Moreira ve ark., 2021). Ayrıca farklı coğrafik konumlarda yapılan çalışmaların daha sıcak ve nemli bölgeler olması da çörek otu tohumlarındaki fungal floradaki çeşitliliği olumlu yönde etkilemiş olabileceği düşünülmektedir (Şekil 1).

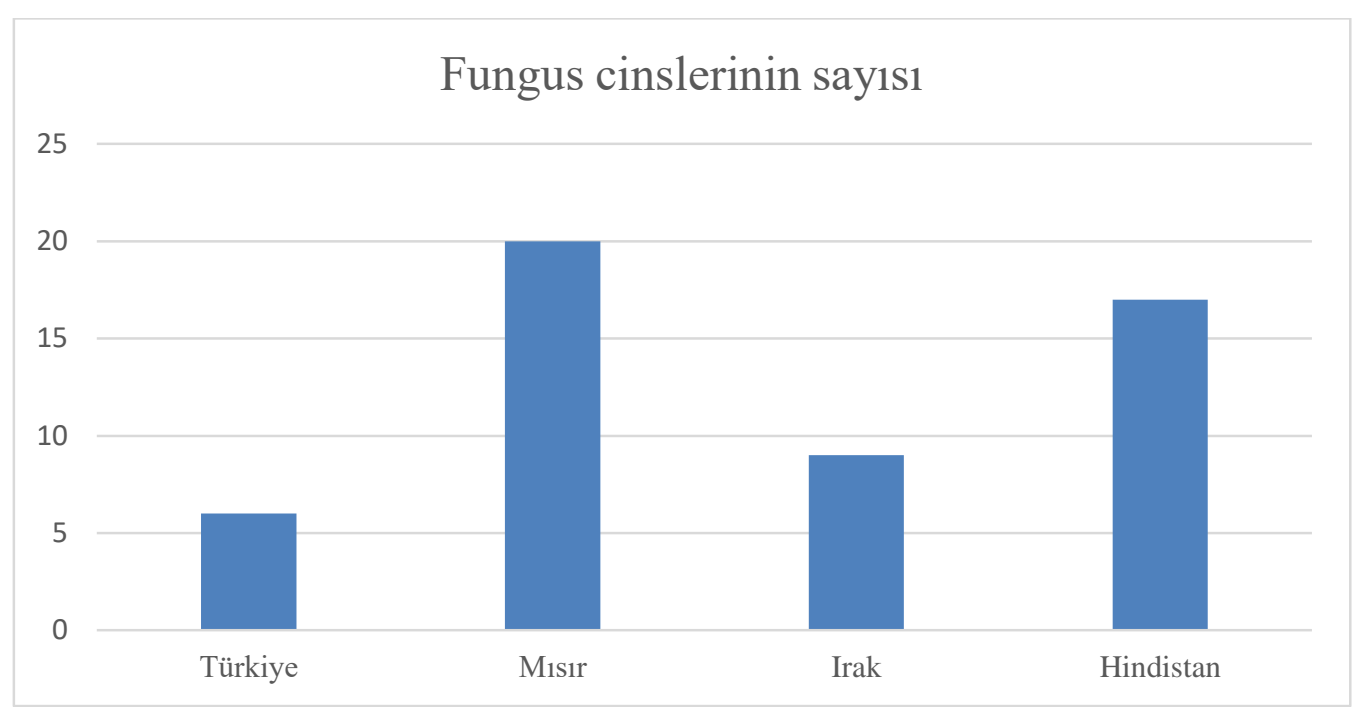

Şekil 1. Çörek otu tohumlarında bulunan fungus cins sayılarının kıyaslanması

Kültüre alma sürecinin de tohum mikrobiyomunu etkilediği bilinmektedir. Örneğin pirinç ve sorgumda kültüre alma sürecinde, qSH1, sh4, ve SpWRKY allellerinin kaybolması yabani türlerde çiçek sapındaki absisyon tabakasının oluşumunu engellemektedir ve bu da tohumun kavuzdan daha hızlı ayırılmasını sağlayarak çıplak tohumların elde edilmesini sağlamaktadır. Kavuzun bu şekilde elemine edilmiş olması tohumlardaki floranın azalmasına neden olmuştur (Hemapriya ve ark., 2020). Çünkü kavuzun tohum için hem bir koruma sağladığı (Radchuk ve Borisjuk, 2014) hem de mikrobiyal popülasyon için bir ekolojik niş görevi gördüğü (Kim ve Lee, 2021) belirtilmektedir. Kültüre alınmış tohumların yabani arpa ve buğdaya göre tohumdan elde edilen mikroorganizma çeşitliliğinin daha fazla olduğu belirtilmiş ancak mikroorganizma-mikroorganizma ilişkisinin yabani tohumlarda daha yoğun olduğu gözlemlenmiştir (Abdullaeva ve ark., 2021)

Diğer yandan, tohum mikrobiyomu, özellikle tohum kökenli endofitler, fitohormonlar, enzimler ve metabolik ürünler salgılayarak bitki performansını ve üretimini arttırdıkları bilinmektedir (Shahzad ve ark., 2018). Bazı çalışmalarda, tohum mikroplarını tekrar bitkiye inokule ettiği zaman bitki gelişim uyarıcılarının aktive olmasını teşvik ettiği gözlemlenmiştir (Mukherjee ve ark., 2020).

\section{SONUÇ}

Tohum mikrobiyomu bitkide gösterdiği pek çok faydasına rağmen fito mikrobiyom alanında muhtemelen en az çalışılan konudur (Chouhan ve ark., 2021). Bu sebepten, gelecek çalışmalarda tohum 
mikrobiyomunun bitkideki rolünün daha iyi anlaşılması ve bu alanın özelliklerinden faydalanabilmek için ıslah programlarına adapte edilmesinin gerektiği düşünülmektedir.

\section{Çıkar Çatışması}

Yazarlar arasında herhangi bir çıkar çatışması yoktur.

\section{Yazar Katkısı}

Yazarlar makaleye eşit oranda katkı sağlamıştır.

\section{KAYNAKLAR}

Abdullaeva Y, Ambika Manirajan B, Honermeier, B Schnell S, Cardinale M, 2021. Domestication Affects the Composition, Diversity, and Co-Occurrence of the Cereal Seed Microbiota. Journal of Advanced Research, 31: 75-86.

Al-Zubaide NA, Al-Kurtany AES, Alwa DS, 2014. Investigation of the Fungi Adherent to Black Cumin Seed (Nigella sativa L.) and Their Effects on Germination Seed. Diyala Journal for Pure Sciences, $10(1)$.

Anonim, 2021. TÜİK, Bitkisel Üretim İstatistikleri, https://data.tuik.gov.tr/Bulten/Index?p=BitkiselUretim-2.Tahmini-2021-37248 (Erişim tarihi:16.11.2021)

Anwar A, Ansari AR, 2016. Studies on Seed Mycoflora of Nigella sativa L. During Pre Harvest, Post Harvest and Storage Conditions. International Journal of Science and Research, 7 (2).

Barret M, Briand M, Bonneau S, Préveaux A, Valière S, Bouchez O, Hunault G, Simoneau P, Jacques MA, 2015. Emergence Shapes the Structure of the Seed Microbiota. Applied and Environmental Microbiology, 81 (4): 1257-1266.

Bever JD, Mangan SA, Alexander, HM, 2015. Maintenance of Plant Species Diversity by Pathogens. Annual Review of Ecology, Evolution, and Systematics, 46 (1): 305-325.

Booth C, 1977. Fusarium: Laboratory Guide to the Identification of the Major Species. Commonwealth Mycological Institution Kew-Surrey.

Chouhan GK, Verma JP, Jaiswal DK, Mukherjee A, Singh S, de Araujo Pereira AP, Liu H, Abd_Allah EF, Singh BK, 2021. Phytomicrobiome for Promoting Sustainable Agriculture and Food Security: Opportunities, Challenges, and Solutions. Microbiological Research, 248: 126763.

Elwakil MA, Ghoneem KM, 1999. Detection and Location of Seed-Borne Fungi of Black Cumin and Their Transmission in Seedlings. Pakistan Journal of Biological Sciences, 2 (2): 559-564.

Fatima S, Khot YC, 2015. Studies on Fungal Population of Cumin (Nigella sativa L.) From Different Parts of Marathwada. Knowledge Scholar, 2 (2).

Forouzanfar F, Bazzaz BSF, Hosseinzadeh H, 2014. Black cumin (Nigella sativa) and its constituent (thymoquinone): a review on antimicrobial effects. Iranian Journal of Basic Medical Sciences, 17 (12): 929-938.

Goreja WG, 2003. Black seed: Nature's Miracle Remedy. Karger Publishers.

Gürer M (Butin, H.), 2000. Orman Ağaçlarında Çiçek ve Tohum Hastalıkları. Orman Ağaçları ve

Tohumları Islah Araştırma Müdürlüğ̈ Yayınları. Sayı: 1, Ankara.

Hardoim PR, van Overbeek LS, Berg G, Pirttilä AM, Compant S, Campisano A, Döring M, Sessitsch A, 2015. The Hidden World within Plants: Ecological and Evolutionary Considerations for Defining Functioning of Microbial Endophytes. Microbiology and Molecular Biology Reviews, 79 (3): 293-320.

Hemapriya M, Nataraja KN, Suryanarayanan TS, Shaanker RU, 2020. Threshing Yards: Graveyard of Maternally Borne Seed Microbiome?. Trends in Ecology \& Evolution, 35 (11): 965-968. 
International Seed Testing Association, 1999. International rules for seed testing. Seed Science and Technology.

Kim H, Lee YH, 2021. Spatiotemporal Assembly of Bacterial and Fungal Communities of SeedSeedling-Adult in Rice. Frontiers in Microbiology, 12: 708475.

Latz MAC, Kerrn MH, Sørensen H, Collinge DB, Jensen B, Brown, JKM, Madsen AM, Jørgensen HJL, 2021. Succession of the Fungal Endophytic Microbiome of Wheat is Dependent on TissueSpecific İnteractions between Host Genotype and Environment. Science of The Total Environment, 759: 143804.

Morales-Moreira ZP, Helgason BL, Germida JJ, 2021. Crop, Genotype, and Field Environmental Conditions Shape Bacterial and Fungal Seed Epiphytic Microbiomes. Canadian Journal of Microbiology, 67 (2): 161-173.

Mukherjee A, Singh BK, Verma JP, 2020. Harnessing Chickpea (Cicer arietinum L.) Seed Endophytes for Enhancing Plant Growth Attributes and Bio-Controlling Against Fusarium sp. Microbiological Research, 237: 126469.

Nelson EB, 2004. Microbial Dynamics and Interactions in the Spermosphere. Annual Review of Phytopathology, 42 (1): 271-309.

Nelson EB, 2017. The Seed Microbiome: Origins, Interactions, And Impacts. Plant and Soil, 422 (1-2): 7-34.

Nelson PE, Toussoun TA, Marasas WFO, 1983. Fusarium Species: an Illustrated Manual for Identification. Pennsylvania State University Press. University Park (Pa.).

Radchuk V, Borisjuk L, 2014. Physical, Metabolic and Developmental Functions of the Seed Coat. Frontiers in Plant Science, 5.

Randhawa MA, Alghamdi MS, 2011. Anticancer Activity of Nigella sativa (Black Seed) - A Review. The American Journal of Chinese Medicine, 39 (06): 1075-1091.

Shahzad R, Khan AL, Bilal S, Asaf S, Lee IJ, 2018. What Is There in Seeds? Vertically Transmitted Endophytic Resources for Sustainable Improvement in Plant Growth. Frontiers in Plant Science, 9: 24. 